\title{
Optimal dose of dexmedetomidine for sedation during spinal anesthesia
}

\author{
Hwoe-Gyeong Ok, Seung-Hoon Baek, Seong-Wan Baik, Hae-Kyu Kim, Sang-Wook Shin, and \\ Kyung-Hoon Kim
}

Department of Anesthesia and Pain Medicine, Pusan National University College of Medicine, Yangsan, Korea

\begin{abstract}
Background: Sedation in spinal anesthesia can reduce patient's anxiety and discomfort. Dexmedetomidine has a sedative, hypnotic, analgesic, and minimal respiratory depression effect. However, use of the dexmedetomidine is associated with prolonged recovery. This study was designed to investigate the optimal dose of intravenous dexmedetomidine for proper sedation with minimal recovery time in spinal anesthesia.
\end{abstract}

Methods: One hundred twenty eight patients, aged 20-70 years (58.8 \pm 0.7 ), were recruited. After performing the spinal anesthesia with hyperbaric bupivacaine $(13 \mathrm{mg})$, a loading dose of dexmedetomidine $(1 \mu \mathrm{g} / \mathrm{kg}) \mathrm{was}$ administered for $10 \mathrm{~min}$, followed by the maintenance infusion of the following: Group A ( $\mathrm{n}=33$; normal saline), Group B ( $\mathrm{n}=35$; dexmedetomidine $0.2 \mu \mathrm{g} / \mathrm{kg} / \mathrm{hr}$ ), and Group C ( $\mathrm{n}=39$; dexmedetomidine $0.4 \mu \mathrm{g} / \mathrm{kg} / \mathrm{hr}$ ). Heart rate, blood pressure, and the bispectral index score (BIS) were recorded during the operation. In the recovery room, modified aldrete score (MAS) was measured.

Results: There were no significant differences in mean blood pressure and heart rate among the three groups. BIS was not significantly different among the three groups from baseline to $60 \mathrm{~min}$ after the infusion of dexmedetomidine. BIS were significantly increased in Group A after 70 and $80 \mathrm{~min}$, and Group A and B after 90, 100, 110 min of dexmedetomidine infusion ( $\mathrm{P}<0.05$ ). MAS was higher in Group A as compared to Group B and C, within 30 min after admission in the recovery room $(\mathrm{P}<0.05)$.

Conclusions: The loading dose $(1 \mu \mathrm{g} / \mathrm{kg} / 10 \mathrm{~min})$ of dexmedetomidine was sufficient for surgery of less than $60 \mathrm{~min}$. Dexmedetomidine infusion followed by maintenance dose $(0.2 \mu \mathrm{g} / \mathrm{kg} / \mathrm{hr})$ was sufficient for surgery within $90 \mathrm{~min}$. (Korean J Anesthesiol 2013; 64: 426-431)

Key Words: Dexmedetomidine, Sedation, Spinal anesthesia.

Received: July 23, 2012. Revised: 1st, October 12, 2012; 2nd, October 31, 2012. Accepted: November 2, 2012.

Corresponding author: Seung-Hoon Baek, M.D., Department of Anesthesia and Pain Medicine, Pusan National University Yangsan Hospital, Beomeo-ri, Mulgeum-eup, Yangsan 626-770, Korea. Tel: 82-55-360-2129, Fax: 82-55-360-2149, E-mail: anebsh@pusan.ac.kr

(c) This is an open-access article distributed under the terms of the Creative Commons Attribution Non-Commercial License (http:// creativecommons.org/licenses/by-nc/3.0/), which permits unrestricted non-commercial use, distribution, and reproduction in any medium, provided the original work is properly cited. 


\section{Introduction}

Spinal anesthesia has the advantage of being able to maintain spontaneous breathing as well as relaxing the necessary muscles for surgery. It also has the advantage of being free from the risks of intubation and pulmonary aspiration. However, the time limit and patients' anxiety of spinal anesthesia present disadvantages. Generally, most failures in regional anesthesia, including spinal anesthesia, are related to inadequate sedation and relief of anxiety rather than technical problems. Adequate sedation in spinal anesthesia relieves the anxiety of the patient, improves physiological and psychological stress, and increases the satisfaction of both the surgeon and patient $[1,2]$.

In spinal anesthesia, propofol and midazolam are commonly used for sedation. Propofol produces rapid and deep decline in the level of consciousness. With a continuous infusion of propofol, the infusion rate can be adjusted to reach the desired level of sedation. Regardless of the length of infusion duration, rapid recovery is seen once infusion is discontinued. However, the use of propofol often leads to a decline in cardiovascular function and respiratory function [3-5]. Although midazolam is a lipid-soluble benzodiazepine with a rapid onset and recovery time, the onset time of midazolam is slower than propofol. Also its clearance time when infused at a high dose is slower than that of propofol. Moreover, midazolam causes a slight drop in blood pressure and mild to moderate respiratory depression [6].

Dexmedetomidine, a selective alpha ${ }_{2}$-adrenergic agonist, affects the locus caeruleus area, which is related to the modulation of sleep regulation and respiratory control, and has a sedative effect. The analgesic effect is due to the activation of the alpha2-adrenergic receptors of the central nervous system $[7,8]$. Dexmedetomidine reduces biological stress responses and reduces the heart rate and blood pressure to moderate levels by lowering catecholamine secretion. It also has minimal or no effect on the respiratory rate and tidal volume [9]. However, the use of dexmedetomidine can cause prolonged recovery $[10,11]$. The use of dexmedetomidine as a sedative in regional anesthesia, such as in epidural anesthesia, spinal anesthesia, and nerve blocks, shows a much greater sedation in the post anesthetic care unit (PACU) compared to the use of propofol [12]. In patients of 65 years and over who had spinal anesthesia with a low dose of bupivacaine, the use of dexmedetomidine had a longer PACU stay than the control group that used normal saline [13].

The present study investigated on the optimal dose of dexmedetomidine with minimal recovery time which gave adequate sedation for spinal anesthesia within $1-2 \mathrm{hr}$.

\section{Materials and Methods}

One hundred and twenty eight patients, aged $20-70$ years, of American Society of Anesthesiologists physical status I and II, were recruited. An anesthesiologist visited the patients who planned to have elective surgery under spinal anesthesia the day before the surgery. Informed consent about the spinal anesthesia and sedation during surgery was obtained. Patients were excluded from the study if they had arrhythmia, heart failure, renal failure, liver failure, or bleeding tendency.

Premedication was not performed. After arrival in the operating room, noninvasive blood pressure, heart rate, oxygen saturation, and bispectral index (BIS) monitoring were performed. Before spinal anesthesia, crystalloid $10 \mathrm{ml} / \mathrm{kg}$ was administered intravenously as prehydration. The patient was placed in the lateral recumbent position and a spinal tap in $\mathrm{L} 3 / 4$ was performed. Hyperbaric bupivacaine $13 \mathrm{mg}$ was administered intrathecally. The patient was then placed in the supine position, and oxygen $3 \mathrm{~L} / \mathrm{min}$ was administered. After the confirmation of successful spinal anesthesia, dexmedetomidine loading dose $1 \mu \mathrm{g} / \mathrm{kg}$ was administered intravenously for $10 \mathrm{~min}$. With different syringes, the maintenance infusion was administered intravenously (Group A: normal saline, Group B: dexmedetomidine $0.2 \mu \mathrm{g} / \mathrm{kg} / \mathrm{hr}$, and Group C: dexmedetomidine $0.4 \mu \mathrm{g} / \mathrm{kg} / \mathrm{hr}$ ). The intravenous administration of dexmedetomidine was discontinued once the surgeon began to suture the surgical site.

Three types of syringes were prepared on $50 \mathrm{ml}$ syringes (Group A: saline $50 \mathrm{ml}$, Group B: a $50 \mathrm{ml}$ mixture of saline $49 \mathrm{ml}$ and dexmedetomidine $100 \mu \mathrm{g}$, and Group C: a $50 \mathrm{ml}$ mixture of saline $48 \mathrm{ml}$ and dexmedetomidine $200 \mu \mathrm{g}$ ). The syringes were prepared in advance by nurses and were chosen by using a table of random numbers.

Noninvasive blood pressure, pulse oxymetry, and BIS were monitored in all patients before surgery, immediately after ending the loading dose of dexmedetomidine, and at $10 \mathrm{~min}$ intervals thereafter. In the PACU after surgery, assigned nurse recorded modified aldrete score (MAS).

The adequate sedation level for surgery was set at mild to moderate, at BIS 60-80. In the PACU, MAS was assessed, which consisted of activity, breathing, circulation, consciousness, and oxygen saturation. The recovery was considered prolonged, when the MAS was under 9 (out of 10), and the duration of stay was longer than $30 \mathrm{~min}$ in the PACU.

Atropine $0.5 \mathrm{mg}$ was administered intravenously when bradycardia (heart rate below 50 beats/min) occurred. Ephedrine $5 \mathrm{mg}$ and crystalloid $300 \mathrm{ml}$ was administered intravenously when hypotension (mean arterial pressure $50 \mathrm{mmHg}$ or below) occurred.

The patients with the surgery lasting more than $2 \mathrm{hr} 30$ min (Group A = 4, Group B = 3, and Group C = 4), and were awake in need of additional sedatives were excluded from the study (Group $A=4$, Group B = 4, and Group C = 2). The final remaining number of patients were 33 in Group A, 35 in Group 
B, and 39 in Group C (Fig. 1).

All data were recorded as mean \pm standard deviation. We used Statview 5.0 (SAS institute, Cary, USA) for statistics. When BIS had a difference of 15 or more, $\alpha$ value was set at 0.05 , and $\beta$ value was set at 0.2 , and the sample size was set at 27 (before starting the intravenous administration of dexmedetomidine, initial BIS was $94.1 \pm 3.5$ ). ANOVA was used to analyze continuous variables, Scheffé's test for posthoc testing, $\chi^{2}$ test on individual patients' statistics, and the Kruskal-Wallis test for MAS in the PACU. P value of 0.05 or below was considered statistically significant.

\section{Results}

There were no significant differences among the three groups in the patient's gender, age, weight, and operating time (Table 1).

BIS started to decline after ending the administration of the loading doses in all groups. There were no differences in BIS among the three groups from the point of administration of the loading dose of dexmedetomidine for $60 \mathrm{~min}$. There were significant differences at $70 \mathrm{~min}$ (Group A: 82.2 $\pm 8.2 \mathrm{~min}$, Group B: $69.2 \pm 16.1 \mathrm{~min}$, and Group C: $69.1 \pm 11.6 \mathrm{~min}$ ) and at $80 \mathrm{~min}$

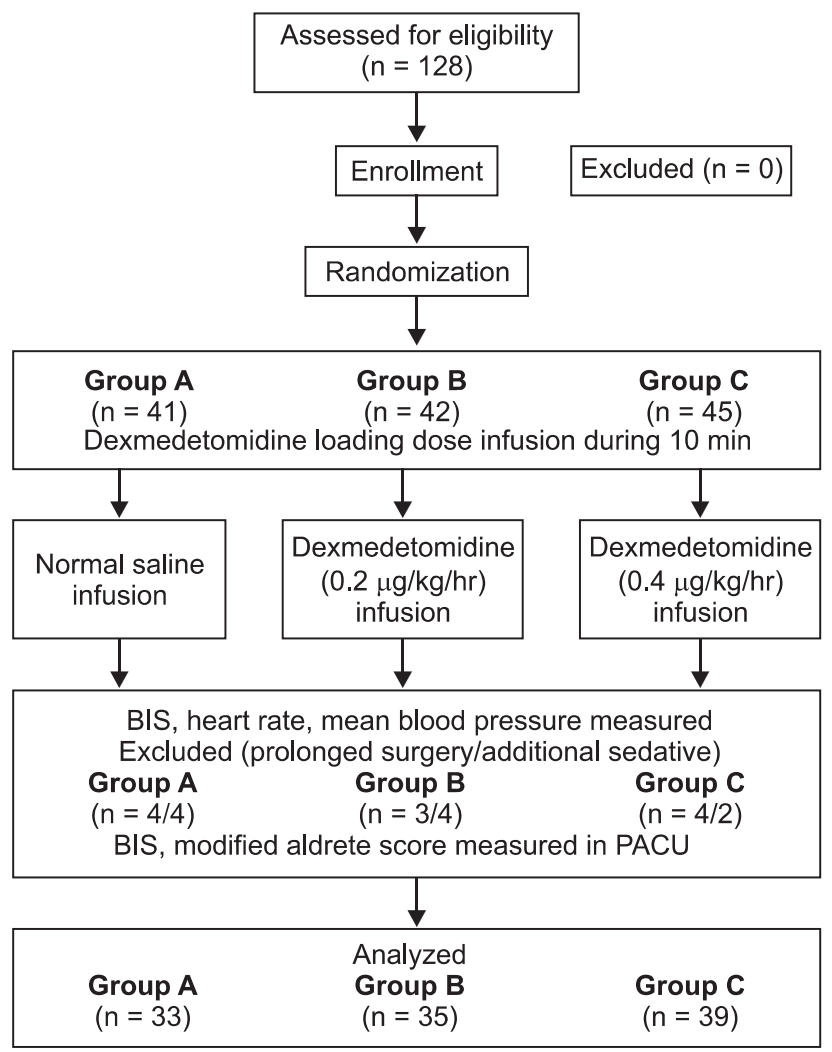

Fig. 1. Flow chart
(Group A: $82.0 \pm 7.6 \mathrm{~min}$, Group B: $72.5 \pm 15.4 \mathrm{~min}$, and Group C: $73.3 \pm 11.0 \mathrm{~min})$. Group A was significantly different compared to Group B and C $(\mathrm{P}<0.05)$ : at $90 \mathrm{~min}$ (Group A: $86.5 \pm 9.2$ min, Group B: $85.1 \pm 9.6 \mathrm{~min}$, and Group C: $71.7 \pm 11.6 \mathrm{~min}$ ); at $100 \mathrm{~min}$ (Group A: $86.6 \pm 7.8 \mathrm{~min}$, Group B: $81.9 \pm 8.4 \mathrm{~min}$, and Group C: $69.1 \pm 8.3 \mathrm{~min}$ ); at $110 \mathrm{~min}$ (Group A: $90.3 \pm 9.3 \mathrm{~min}$, Group B: $83.9 \pm 10.4 \mathrm{~min}$, and Group C: $74.6 \pm 12.0 \mathrm{~min}$ ); and at $120 \mathrm{~min}$ (Group A: $89.7 \pm 8.1 \mathrm{~min}$, Group B: $83.4 \pm 11.1 \mathrm{~min}$, and Group C: $78.3 \pm 10.2 \mathrm{~min})$. Groups A and B showed significant differences compared to Group $\mathrm{C}(\mathrm{P}<0.05)$ (Fig. 2).

The heart rate and mean arterial pressure showed a decrease, but there were no significant differences among the three groups (Fig. 3).

In the PACU, MAS was significantly high for $30 \mathrm{~min}$ in Group A compared to Group B and C $(\mathrm{P}<0.05)$ (Fig. 4).

Table 1. Demographic Data

\begin{tabular}{lccc}
\hline \multicolumn{1}{c}{ Group } & $\mathrm{A}(\mathrm{n}=33)$ & $\mathrm{B}(\mathrm{n}=35)$ & $\mathrm{C}(\mathrm{n}=39)$ \\
\hline Sex (M/F) & $19 / 14$ & $19 / 16$ & $20 / 19$ \\
Age (yr) & $57.2 \pm 7.7$ & $58.3 \pm 11.0$ & $55.9 \pm 12.6$ \\
Weight (kg) & $63.9 \pm 8.4$ & $65.4 \pm 8.2$ & $63.5 \pm 8.0$ \\
Op time (min) & $102.4 \pm 25.2$ & $101.1 \pm 33.8$ & $93.6 \pm 28.3$ \\
DMT time (min) & 10 & $92.4 \pm 34.3$ & $90.2 \pm 29.2$ \\
\hline
\end{tabular}

Data are presented as mean \pm standard deviation. There are no significant statistical differences among the three groups. Op time is operation time. DMT time is dexmedetomidine infusion time.

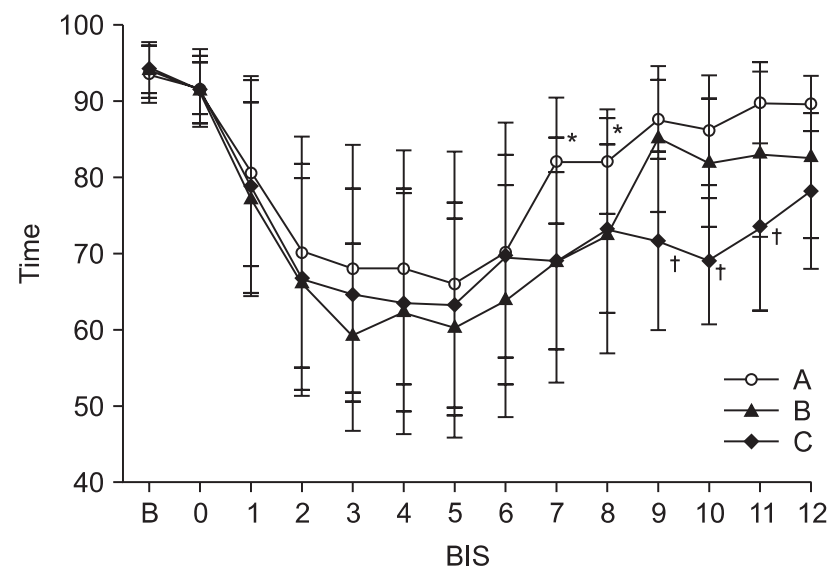

Fig. 2. Intraoperative changes (10 minute interval) in bispectral index (BIS) after intravenous infusion of the dexmedetomidine. Data are presented as mean \pm standard deviation. ${ }^{*} \mathrm{P}<0.05$ compared with Group B and C, ${ }^{\dagger} \mathrm{P}<0.05$ compared with Group A and B. A: loading dose $(1 \mu \mathrm{g} / \mathrm{kg} / 10 \mathrm{~min})$ only, B: loading dose followed by maintenance dose $(0.2 \mu \mathrm{g} / \mathrm{kg} / \mathrm{hr})$, C: loading dose followed by maintenance dose $(0.4 \mu \mathrm{g} / \mathrm{kg} / \mathrm{hr})$, BIS 0 : bispectral index value of the dexmedetomidine infusion start time. 

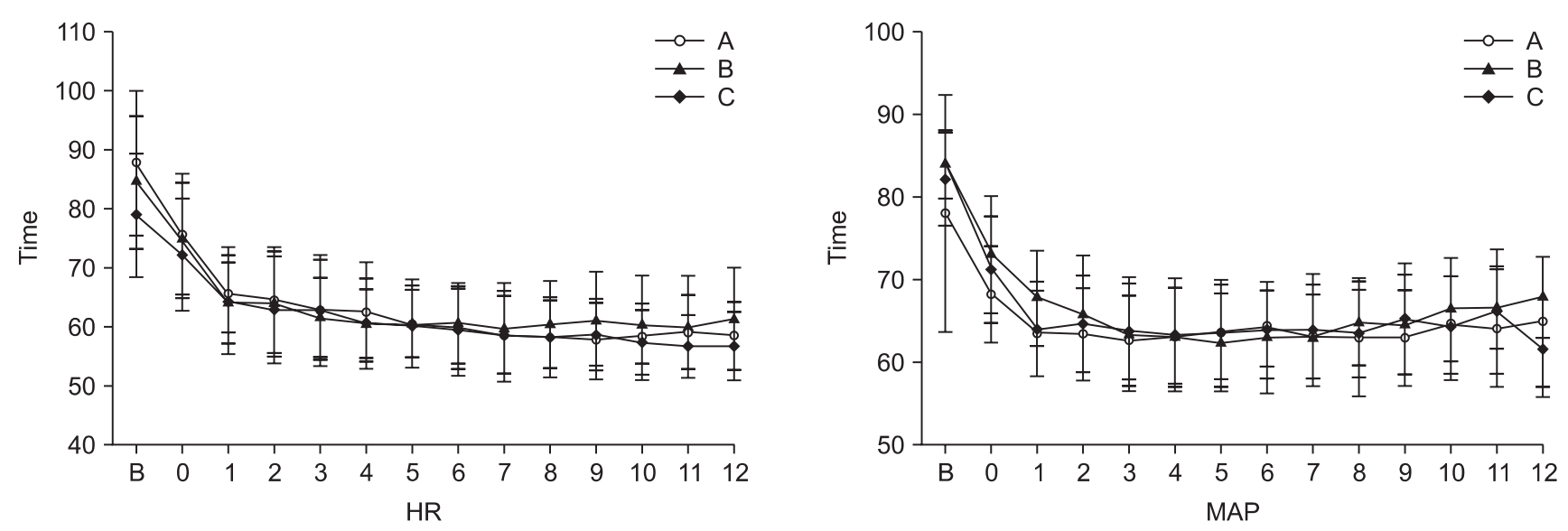

Fig. 3. Intraoperative changes (10 minute interval) in heart rate and mean arterial pressure after intravenous infusion of the dexmedetomidine. Data are presented as mean \pm standard deviation. A: loading dose $(1 \mu \mathrm{g} / \mathrm{kg} / 10 \mathrm{~min})$ only, B: loading dose followed by maintenance dose ( 0.2 $\mu \mathrm{g} / \mathrm{kg} / \mathrm{hr})$, C: loading dose followed by maintenance dose $(0.4 \mu \mathrm{g} / \mathrm{kg} / \mathrm{hr})$, HR 0 : heart rate of the dexmedetomidine infusion start time, MAP 0 : mean arterial pressure of the dexmedetomidine infusion start time.
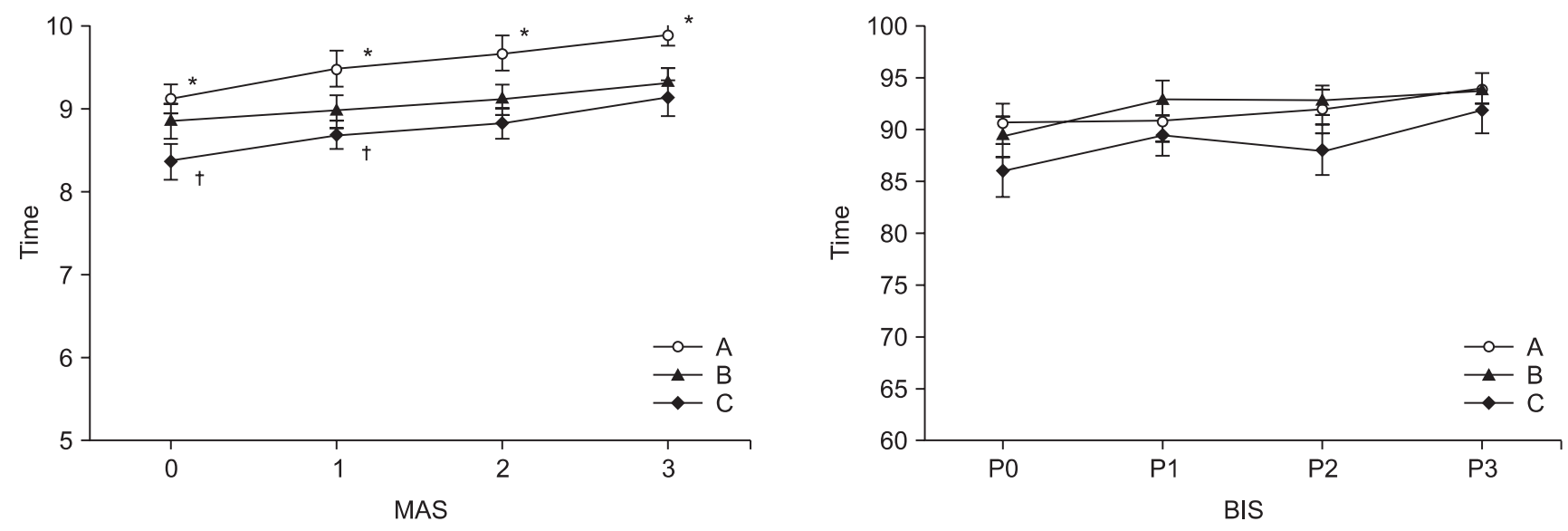

Fig. 4. Postoperative changes (10 minute interval) in modified aldrete score (MAS) and bispectral index (BIS) after admission to the recovery room. Data are presented as mean \pm standard deviation. ${ }^{*} \mathrm{P}<0.05$ compared with Group B and $\mathrm{C},{ }^{\dagger} \mathrm{P}<0.05$ compared with Group B. A: loading dose $(1 \mu \mathrm{g} / \mathrm{kg} / 10 \mathrm{~min})$ only, B: loading dose followed by maintenance dose $(0.2 \mu \mathrm{g} / \mathrm{kg} / \mathrm{hr})$, C: loading dose followed by maintenance dose $(0.4 \mu \mathrm{g} / \mathrm{kg} / \mathrm{hr})$, MAS 0 : modified aldrete score at the moment of the recovery room arrival, BIS P0: bispectral index value at the moment of the recovery room arrival.

\section{Discussion}

In spinal anesthesia, using no maintenance dose after a loading dose of dexmedetomidine $1 \mu \mathrm{g} / \mathrm{kg}$ brought adequate sedation within $60 \mathrm{~min}$. An infusion of a maintenance dose of $0.2 \mu \mathrm{g} / \mathrm{kg} / \mathrm{hr}$ brought adequate sedation within $80 \mathrm{~min}$, and an infusion of a maintenance dose of $0.4 \mu \mathrm{g} / \mathrm{kg} / \mathrm{hr}$ brought adequate sedation within $120 \mathrm{~min}$.

The distribution half-life of dexmedetomidine is known to be 5 to $10 \mathrm{~min}$. The termination half-life is known to be within $2-3 \mathrm{hr}$; and it is similar in healthy Koreans. It has been reported that dexmedetomidine has linear pharmacokinetic characteristics and dose-dependent sedation effects [14]. Lee et al. [14] reported that when a loading dose of dexmedetomidine
$1 \mu \mathrm{g} / \mathrm{kg}$ for $10 \mathrm{~min}$ was administered and infused continuously, on the average, the peak concentration was reached in $17 \mathrm{~min}$, and the termination half-life was $2 \mathrm{hr}$ and $10 \mathrm{~min}$. We believed that the loss of sedative effects occurs at around 60 min after the administration of a loading dose without continuous infusion. It was reported that when an MRI was taken in a pediatric patient who needed the sedation of within $60 \mathrm{~min}$, even with a high dose administration of dexmedetomidine $(2-3 \mu \mathrm{g} / \mathrm{kg} / 10$ min loading dose), the adequate sedation was not achieved and additional drugs were needed [15]. However, in the case of spinal anesthesia, the spinal anesthesia itself is reported to have sedative effects and a low loading dose of dexmedetomidine alone is believed to bring adequate sedation [16]. Depending on the dose of continuous intravenous administration after the 
administration of loading dose, the difference in duration of sedation is believed to be dependent on the aforementioned linear pharmacokinetic characteristics. In this study, the number of patients within 90 min from the loading dose infusion of dexmedetomidine satisfied the sample size, but the number of patients over $90 \mathrm{~min}$ from the loading dose infusion of dexmedetomidine was lower than the sample size. As such, a further study is necessary for sedation over $2-3 \mathrm{hr}$.

In general, the Ramsay sedation score and the observer's assessment of alertness and sedation (OAA/S) score are commonly used to assess sedation. However, the disadvantages of these assessment methods are that the sedated patient must be alert for assessment, and that the assessor makes a subjective assessment depending on the patient's response. Moreover, a real time assessment is difficult. BIS monitoring has the advantage that sedation can be maintained without external stimulation, and the objective, real-time assessment is possible. BIS values are correlated to anesthetic depth of inhalational anesthesia and intravenous anesthesia, and also correlated to sedation using propofol and midazolam $[17,18]$. Liu et al. [19] reported that OAA/S scores and BIS are correlated to the alert state, sedation state, and deep sedation state. Sleigh et al. [20] stated BIS is an index for consistent monitoring of the depth of sleep.

In a study comparing BIS and OAA/S in the sedation using dexmedetomidine and propofol, $85 \%$ of the patients showed $40-$ 60 of BIS value, a deep sedation state, in the dexmedetomidine group when the OAA/S score was 3 , which was a relatively greater sedation score than the propofol group. We set BIS for adequate sedation level at $60-80$. Sedation was maintained well except the small number of patients who needed additional sedation during surgery. As such, the sedation using dexmedetomidine, with BIS as the sedation index, showed different results as compared to the study by Kasuya et al. [21] As aforementioned, the sedation effects of spinal anesthesia itself, and the fact that the spinal anesthesia and sedation were induced simultaneously, could induce sedation even at a high BIS value. Relatively low dose of dexmedetomidine can also induce sedation at a high BIS value. Unlikely other drugs, dexmedetomidine affects the locus caeruleus and induces sedation. Its pattern is more similar to sleep than sedation. As aforementioned, it is reported that BIS is related to the depth of sleep, and it may be also applied to the effects of sedation using dexmedetomidine. Further study is required on whether dexmedetomidine has an effect on BIS itself, and the possible dose-dependent difference.

Spinal anesthesia is often used for ambulatory surgery. It is necessary to reduce the time of stay in the PACU, and this is especially important for patients who have had spinal anesthesia with sedation. The group that was administered only a loading dose had a MAS which allowed the patient to be discharged at the time of arrival in PACU. However, a low dose of dexmedetomidine was infused in all three groups, and the patients had appropriate MAS for discharge within $30 \mathrm{~min}$. In the PACU, BIS were approximately 90 in all groups, and there was no significance.

There is a report that dexmedetomidine used for sedation delays the patients' recovery. In those cases, the loading dose was administered, then a maintenance dose of $0.6 \mu \mathrm{g} / \mathrm{kg} /$ hr or more was used, which was different from the present study $[10,11]$. However, when dexmedetomidine was used in pediatrics for the sedation for an MRI, it was reported that there was no correlevance between recovery time and dose [22]. Although spinal anesthesia with a low dose of dexmedetomidine was performed in this study, and we did not observe delayed recovery, it is difficult to compare recovery profiles with only simple comparisons in the PACU.

The greatest benefit of sedation by dexmedetomidine administration is that it can cause sedation without respiratory depression, and respiratory depression was not observed in our study. In general, the most common side effects of dexmedetomidine are hypotension and bradycardia. When dexmedetomidine is used with spinal anesthesia, it may increase the frequency of such side effects. In this study, there was no case of hypotension that needed rescue drugs; however, bradycardia that needed rescue drugs occurred in 3 patients in Group A, 3 patients in Group B, and 1 patient in Group C. There is a report of bradycardia and hypotension occurring in pediatric patients with a large amount of dexmedetomidine administered [22]. It is likely that the frequency of bradycardia and hypotension does not increase when a low dose of dexmedetomidine is administered with spinal anesthesia.

The use of dexmedetomidine causes sedation, but because the patient can be aroused at anytime, it is commonly used in sedation for procedure. The limitation of the present study is that dexmedetomidine was administered after performing spinal anesthesia. When sedation is performed for the purpose of reducing patient anxiety during surgery, it is believed that adequate sedation effect needs to precede the start of the surgery, ideally. As soon as the patient is on the operating table, the infusion needs to be started, and it helps to reduce anxiety from spinal anesthesia itself and dexmedetomidine's relatively long onset time.

In conclusion, dexmedetomidine can be useful in spinal anesthesia for sedation. For surgeries within $1 \mathrm{hr}$, sedation can be induced by only $1 \mu \mathrm{g} / \mathrm{kg} / 10 \mathrm{~min}$ loading dose. For surgeries within $90 \mathrm{~min}, 0.2 \mu \mathrm{g} / \mathrm{kg} / \mathrm{hr}$ maintenance dose can produce sedation without delayed recovery. 


\section{References}

1. American Society of Anesthesiologists Task Force on Sedation and Analgesia by Non-Anesthesiologists. Practice guidelines for sedation and analgesia by non-anesthesiologists. Anesthesiology 2002; 96: 1004-17.

2. De Andres J, Valia JC, Gil A, Bolinches R. Predictors of patient satisfaction with regional anesthesia. Reg Anesth 1995; 20: 498-505.

3. Ozkan-Seyhan T, Sungur MO, Senturk E, Karadeniz M, Basel A, Senturk M, et al. BIS guided sedation with propofol during spinal anaesthesia: influence of anaesthetic level on sedation requirement. Br J Anaesth 2006; 96: 645-9.

4. Blouin RT, Seifert HA, Babenco HD, Conard PF, Gross JB. Propofol depresses the hypoxic ventilatory response during conscious sedation and isohypercapnia. Anesthesiology 1993; 79: 1177-82.

5. Sharma VK, Galli W, Haber A, Pressman MR, Stevenson R, Meyer TJ, et al. Unexpected risks during administration of conscious sedation: previously undiagnosed obstructive sleep apnea. Ann Intern Med 2003; 139: 707-8.

6. Patki A, Shelgaonkar VC. A comparison of equisedative infusions of propofol and midazolam for conscious sedation during spinal anesthesia - a prospective randomized study. J Anaesthesiol Clin Pharmacol 2011; 27: 47-53.

7. Kamibayashi T, Maze M. Clinical uses of alpha 2-adrenergic agonists. Anesthesiology 2000; 93: 1345-9.

8. Issa FG. Effect of clonidine in obstructive sleep apnea. Am Rev Respir Dis 1992; 145: 435-9.

9. Hsu YW, Cortinez LI, Robertson KM, Keifer JC, Sum-Ping ST, Moretti EW, et al. Dexmedetomidine pharmacodynamics: part I: crossover comparison of the respiratory effects of dexmedetomidine and remifentanil in healthy volunteers. Anesthesiology 2004; 101: 1066-76.

10. Zeyneloglu P, Pirat A, Candan S, Kuyumcu S, Tekin I, Arslan G. Dexmedetomidine causes prolonged recovery when compared with midazolam/fentanyl combination in outpatient shockwave lithotripsy. Eur J Anaesthesiol 2008; 25: 961-7.

11. Makary L, Vornik V, Finn R, Lenkovsky F, McClelland AL, Thurmon J, et al. Prolonged recovery associated with dexmedetomidine when used as a sole sedative agent in office-based oral and maxillofacial surgery procedures. J Oral Maxillofac Surg 2010; 68: 386-91.

12. Arain SR, Ebert TJ. The efficacy, side effects, and recovery characteristics of dexmedetomidine versus propofol when used for intraoperative sedation. Anesth Analg 2002; 95: 461-6.

13. Hong JY, Kim WO, Yoon Y, Choi Y, Kim SH, Kil HK. Effects of intravenous dexmedetomidine on low-dose bupivacaine spinal anaesthesia in elderly patients. Acta Anaesthesiol Scand 2012; 56: 382-7.

14. Lee S, Kim BH, Lim K, Stalker D, Wisemandle W, Shin SG, et al. Pharmacokinetics and pharmacodynamics of intravenous dexmedetomidine in healthy Korean subjects. J Clin Pharm Ther 2012; 37: 698-703.

15. Mason KP, Zurakowski D, Zgleszewski SE, Robson CD, Carrier M, Hickey PR, et al. High dose dexmedetomidine as the sole sedative for pediatric MRI. Paediatr Anaesth 2008; 18: 403-11.

16. Pollock JE, Neal JM, Liu SS, Burkhead D, Polissar N. Sedation during spinal anesthesia. Anesthesiology 2000; 93: 728-34.

17. Vernon JM, Lang E, Sebel PS, Manberg P. Prediction of movement using bispectral electroencephalographic analysis during propofol/ alfentanil or isoflurane/alfentanil anesthesia. Anesth Analg 1995; 80: 780-5.

18. Sandler NA, Hodges J, Sabino M. Assessment of recovery in patients undergoing intravenous conscious sedation using bispectral analysis. J Oral Maxillofac Surg 2001; 59: 603-11.

19. Liu J, Singh H, White PF. Electroencephalographic bispectral index correlates with intraoperative recall and depth of propofol-induced sedation. Anesth Analg 1997; 84: 185-9.

20. Sleigh JW, Andrzejowski J, Steyn-Ross A, Steyn-Ross M. The bispectral index: a measure of depth of sleep? Anesth Analg 1999; 88: 659-61.

21. Kasuya Y, Govinda R, Rauch S, Mascha EJ, Sessler DI, Turan A. The correlation between bispectral index and observational sedation scale in volunteers sedated with dexmedetomidine and propofol. Anesth Analg 2009; 109: 1811-5.

22. Siddappa R, Riggins J, Kariyanna S, Calkins P, Rotta AT. High-dose dexmedetomidine sedation for pediatric MRI. Paediatr Anaesth 2011; 21: 153-8. 